Nippon Suisan Gakkaishi $\quad 53(2), 223-227(1987)$

\title{
Swimming Speed of Sardine School on the Basis of Aerial Survey*1
}

\author{
Ichiro Hara*2
}

(Accepted June 19, 1986)

\begin{abstract}
The flight surveys were conducted in the waters off the southeast coast of Hokkaido where a big catch of sardine Sardinops melanosticta has been taken during summer and autumn seasons. In order to examine the swimming speeds of schools, two kinds of survey, such as experiments and observations, were conducted near the fishing ground on Oct. 9 and Sept. 29, 1985 respectively. In the experiments five floaters were airdropped at a regular interval to intersect the target schools from the rear to the front. After that, relative changes between the school and the floaters were compared. On the other hand, the observations was carried out shuttling the same transect in order to observe the movements of a number of schools. From the results of the experiments the cruising speeds lie between $1.2-4.1 \mathrm{BL} / \mathrm{s}(0.4-1.5 \mathrm{kt})$. The result obtained by the observation was $4.3 \mathrm{kt}$, which was larger compared with the data described above. The schools which were chosen as the subject in the experiments were elongate in shape and the longest dimensions of the schools ranged from $300-1,500 \mathrm{~m}$. The results may suggest that the size of schools have an effect on the speed, as the speed of school decreases with an increase in size.
\end{abstract}

Swimming speed of fish have been studied by numerous authors. There are two aspects to be considered; the maximum speed and the cruising speed or the maximum sustained speed. The definitions for these two swimming speeds are not clear and accurate, because of the variety in the methods and devices which have been used to assess the speeds of the fish. Especially the definition of the cruising speed is different from each investigators, e.g. 20 to $25 \mathrm{~min}$ by Fry and Hert, ${ }^{12} 60 \mathrm{~min}$ by Brett ${ }^{2,3)}$ and varying length of times by Beamish.4) In any case, it can be said that the cruising speed is maintained for a fairly long period of time in the order of 10-60 min.

The swimming speed at which fish schools can swim is of interest in connection with their immigration to and emigration from fishing ground, and with operations by purse seiners. Most of the published works on the swimming speed of fish is concerned with laboratory studies and there are few data in nature, and that very little is known about the swimming speed of schools. Then, the cruising speed of Japanese sardine Sardinops melanosticta schools on the basis of aerial surveys are discussed here.

\section{Materials and Methods}

The work was planned to be undertaken in the area where big catches of sardine have been taken by 24 commercial purse seiners since 1976 . The site was chosen in the waters off the southeastern coast of Hokkaido as sardine schools are observed in great quantity during summer and autumn seasons there..$^{3-7)}$

The flight surveys using Cessna U-206G aircraft were conducted twice under the calm sea conditions during the day hours with two spotter pilots and the author himself on September 29 and October 9, 1985.

The experiments on October 9 were carried out making 3 schools an object in the following way. At first, 5 floaters with a seamarker were airdropped at a regular interval to intersect from the rear to the front of the school. Secondly, relative positions of the school and the floaters were determined by means of the aerial photography. Timing of movement of the schools relative to the floaters was done by a clock in a $35 \mathrm{~mm}$ camera. Since the seamarker contained fluorescein sodium salt (uranin) diffuses yellow-colored particles after a while airdropped into the sea, the floaters and the school which is only distinguished with

*1 Contribution from the Tokai Reg. Fish. Res. Lab., No. B769.

*2 Tokai Regional Fisheries Research Laboratory, Kachidoki, Chuo, Tokyo 104, Japan (原 一郎：東海区 水産研究所). 


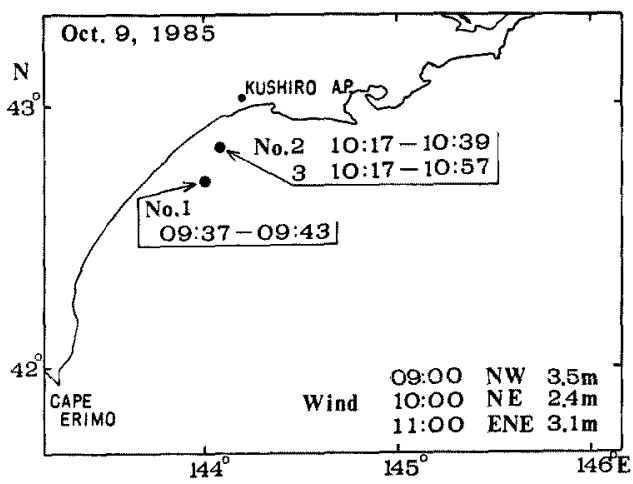

Fig. 1. The sea area that the flight experiments were done using the floaters with seamarker on October 9,1985 . The data on wind was obtained from the HIROO meteorological station at $42^{\circ} 17^{\prime} \mathrm{N}, 143^{\circ} 20^{\prime} \mathrm{E}$.

dark color against lighter background of the sea are very easy to observe. ${ }^{6,7)}$ The influence of environmental factors, such as wind force and surface current, on the floaters was ignored in case of analysing, although the floaters had been moving only a short distance on the effect of the wind forth.

The observation on September 29 was carried out shuttling the same transect in order to observe the movements of a number of schools.

\section{Results}

The experiments of tracking three schools on October 9 were carried out at two spots as is shown in Fig. 1. The time tracked were $6 \mathrm{~min}$ (09:37-09:43) for the school No. 1, $22 \mathrm{~min}$ $(10: 17-10: 39)$ for the No. 2 , and $40 \mathrm{~min}(10: 17-$ 10:57) for the No. 3, respectively. Although the direction of the wind changed slowly from NW to ENE with time, the sea condition was calm and the wind force was stable about $3 \mathrm{~m} / \mathrm{s}$ during the survey. Fig. 2 shows the direction of the floaters and the schools. The distance among the floaters was estimated from the speed of aircraft and the time required for the five floaters to be airdropped at a regular interval. At the spot where the school No. 1 was observed, the course line of five floaters was stable in $202^{\circ}$ direction and the relative positions of each five floaters, which was $139 \mathrm{~m}$ apart from each other, were also stable during the observation. On the other hand, at the spot where the schools No. 2, 3 were observed, the direction of the course line of five floaters changed

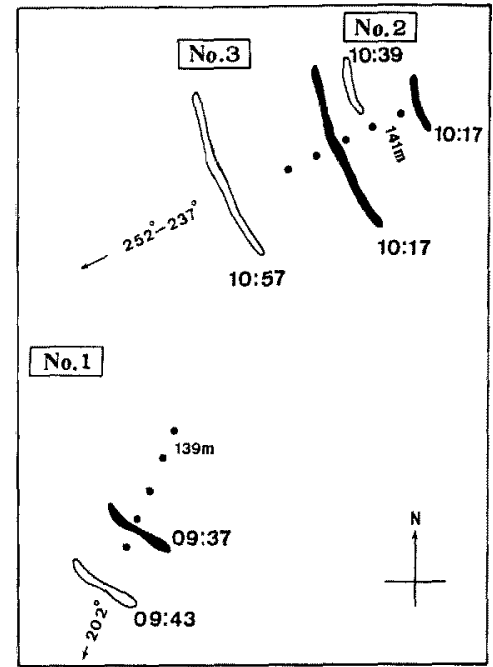

Fig. 2. The changes of three elongate shape schools which were sketched from the oblique photographs. The three elongate black shapes show the positions of schools at the beginning of experiments and the white ones show at the ending.

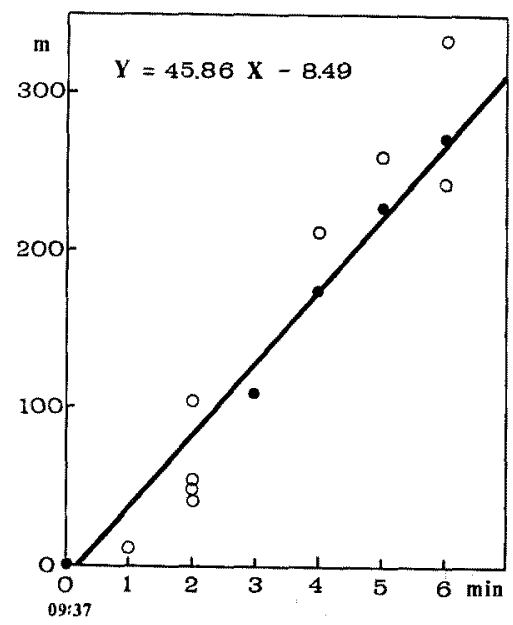

Fig. 3. The relationship between the time and the position of the school No. 1.

slowly from $252^{\circ}$ (time $10: 17$ ) to $237^{\circ}$ (time $10: 43$ ), although the relative positions of each five floaters did not change, but kept $141 \mathrm{~m}$ distance from each other. Figs. 3-5 show the relationships between the time which required since the observation was started, and the position of the school moved which was expressed in values relative to the floaters. The positions of schools at the beginning of the observations coincide with 


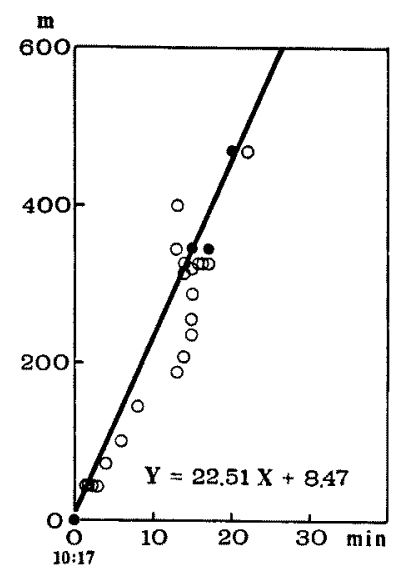

Fig. 4. The relationship between the time and the position of the school No. 2 .

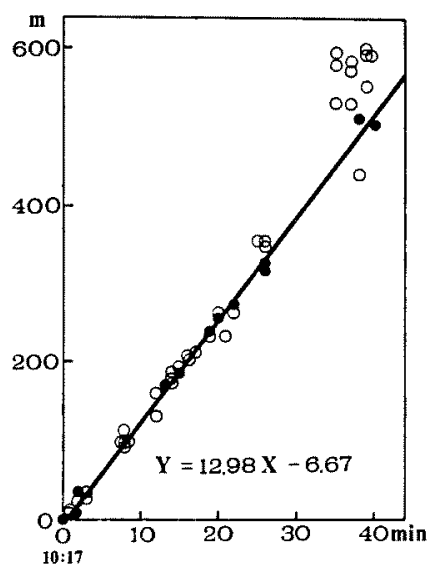

Fig. 5. The relationship between the time and the position of the school No. 3 .

the origin in the figures respectively. The black circles in the figures show the results of the oblique photographs taking from the side to the course line of floaters or the moving direction of the schools. On the other hand, the open circles were not so good conditions because of taking from unsuitable angles against the course line. It is clear from these graphs that the position against the elapsed time suggests a straight line. This gives the uniform velocity of the school which was fairly constant, especially on the black circles. Then, using the least squares method, the results of the linear regression against the black circles are shown in the figures. The speeds of the schools obtained by the slope of the lines are
Table 1. Swimming speeds of sardine schools

\begin{tabular}{|c|c|c|c|}
\hline \multirow[b]{2}{*}{ Experiment 1} & \multicolumn{2}{|c|}{ Swimming speed } & $\begin{array}{l}\text { School size } \\
\text { Longest }\end{array}$ \\
\hline & $4.1 \mathrm{BL} / \mathrm{s}$ & $1.5 \mathrm{kt}$ & $300 \mathrm{~m}$ \\
\hline 2 & $2.0 \mathrm{BL} / \mathrm{s}$ & $0.8 \mathrm{kt}$ & $300 \mathrm{~m}$ \\
\hline 3 & $1.2 \mathrm{BL} / \mathrm{s}$ & $0.4 \mathrm{kt}$ & $1,000-1,500 \mathrm{~m}$ \\
\hline Observation & $11.8 \mathrm{BL} / \mathrm{s}$ & $4.3 \mathrm{kt}$ & \\
\hline Sonar & & $-1.0 \mathrm{kt}$ & \\
\hline
\end{tabular}

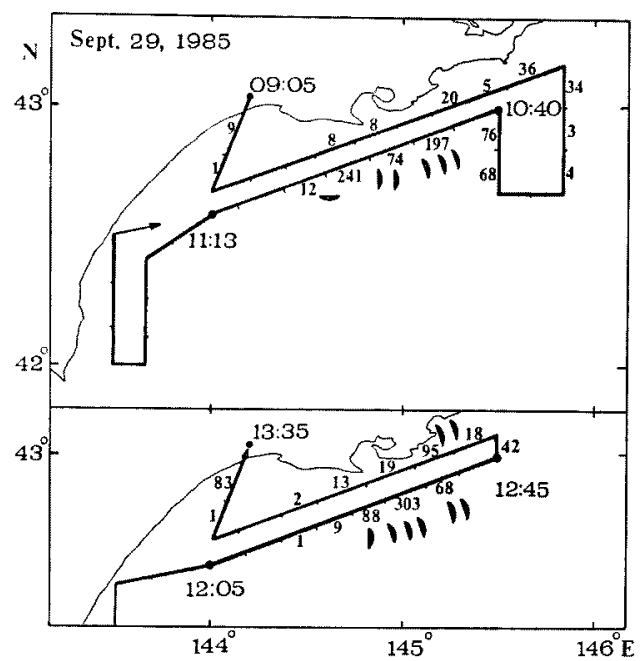

Fig. 6. The transect of the visual observation on Sept. 29, 1985. The number shows sardine schools in a swath which is approximately 1,000 $m$ wide. The crescent mark expressed the sharp which moves towards the head of the crescent.

shown in Table 1. Besides, the speeds calculated as body lengths per second (BL/s) are also expressed, supposing the body length of sardine schools was $18.75 \mathrm{~cm}$ which is the mode of the body length composition of the commercial purse seine catches at the same time.

Fig. 6 shows the transect and the result of the visual observation on September 29, 1985 at an altitude of $500 \mathrm{~m}$. The transect shuttled was set in parallel to the moving direction of schools on the basis of the preliminary aerial survey on September 28. The detailed transect is shown in Fig. 7, in which a number of the schools and the transit time at several points are expressed. A number of schools, which were counted every five minutes during the going to trip from the point at 10:40 to $11: 13$, are shown above the transect 


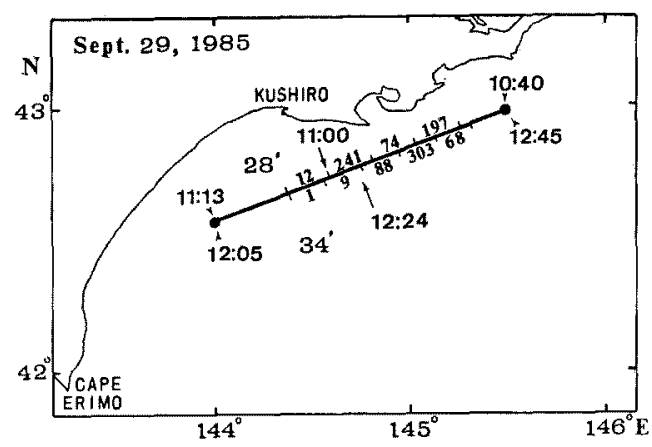

Fig. 7. The detailed transect which is a part of Fig. 6 .

line, and a number of schools during the coming back trip from 12:05 to 12:45 are also shown below the transect line. There is the difference of time elapsed between the going to and the returning flight, because of the effect of the easterly $3-5 \mathrm{~m} / \mathrm{s}$ wind. We assume that every schools had been moving in parallel to the transect during the double-trip flight, because there is no significant difference of the counts between the going to and the coming back flight; 524 schools and 469 schools, respectively. Then, the swimming speed of the whole schools are estimated by timing the movement of the rear part of the moving schools on the transect as follows. On the course of the going to flight, the schools, which had been continuously observed from 10:45, disappeared suddenly at 11:00 at the point 28 nautical miles distant from the point at 11:13 (same as 12:05). On the course of the coming back flight, few schools were observed from 12:05 to $12: 24$. A number of schools appeared suddenly at $12: 24$ at the point 34 nautical miles distant from the point at 12:05 (same as 11:13). Using the change which appeared in the position of the rear of the moving schools, we can calculate the speed of the schools as follows;

$$
(34-28 \mathrm{n} . \mathrm{m} .) /(12: 24-11: 00)=4.3 \mathrm{kt} \text {. }
$$

This is equivalent to $11.8 \mathrm{BL} / \mathrm{s}$ in the same manner as described above.

On the other hand, in order to obtain the speeds of the schools under the ship, the surveys on the basis of scanning sonar were conducted seven times on July 19, August 4 and 14, 1985. The results are shown in Table 1 for reference.

\section{Discussion}

Most of the published works on the swimming speeds of fish has been reviewed by Bainbridge ${ }^{\text {) }}$ and Blaxter. ${ }^{8)}$ According to them the cruising speeds, in general, lie between 2 and $3 \mathrm{BL} / \mathrm{s}$, though salmonids and clupeids can probably maintain $4 \mathrm{BL} / \mathrm{s}$ or more. These data show the typical cruising speed of fish.

The swimming speed of schools in the shallow layer near surface has been described on the basis of aerial surveys. Although the cruising speed is not cleally defined, we could track the three different schools as long as $6-40 \mathrm{~min}$. Then, we could consider the results obtained on October 9 as the cruising speed of sardine schools. Villavicencio et al. ${ }^{10)}$ reported that the Peruvian sardine Sardinops sagax could sustain $3.75 \mathrm{BL} / \mathrm{s}$ for over $1 \mathrm{~h}$. The result obtained on September 29 was $4.3 \mathrm{kt}$, which was larger comparing with the results described above. The discrepancy might be due to the observational errors and the environmental factors, such as the method of observation, the wind effect on the aircraft, the identification of schools. On the other hand, the results on the basis of scanning sonar, which ranges from 0.4 to $1.0 \mathrm{kt}$, support the three experiments on October 9, although the ship's effect on a school was not clear. It becomes a serious problem how fish schools swim in shape and size in case of measuring the swimming speeds of schools. $\mathrm{Hara}^{\left.8,{ }^{7}\right)}$ reported that the sardine school shapes are usually elongate and slender, but they are classified into three types, such as oval, crescent and elongate. Furthermore, they divided roughly in the following two trend: namely schools are stagnant and small quantity in the morning, and schools are numerous and actively move in the afternoon. The target schools moving with the long axis in line were elongate in shape and the longest dimensions of the schools were ranged $300-1,500 \mathrm{~m}$. They did not change in shape and size during the experiments very much. The results may suggest that the size of schools have an effect on the speed, as the speed of school decrease with an increase in size. It has been said that the cruising speed may vary with temperature and current, or there was no obvious correlation between speed and temperature. ${ }^{1,11,12)}$ The environmental effect on swimming speed may vary with conditions. On the biotic effect in a school, a school may be of varying density in different parts, and the orientation may also be diverse, being most clearly expresses in the front part and at the edges but not at all in the rear. Hara") reported that the front of the sardine schools, which indicates the direction of movement, is dark blue and the rare is watery blue in 
color. Although in fact the size, form, structure of schools and density in a school are variable, we suppose here that fish in a school are always orientated in one direction moving at the same speed.

Schooling is a prominent characteristic of pelagic fish and may keep the optimal formation and spacing of fish in a school. These might be concerned with the speed of schools. In addition, the swimming speed of schools may be affected by the shape and size of schools, the length of fish in a school and annual life cycle. More field observations on the speed of schools are planned to look into these matters in future.

\section{Acknowledgements}

The author is grateful to his colleagues of Fisheries Resources Division, Tokai Regional Fisheries Research Laboratory for useful suggestions and encouragements during this work. The author also thanks the Section of Fish Resources, Fishery Agency, for the financial support to accomplish this study. The work was carried with the cooperation of the two spotter pilots of the Fishery Aviation Co., Ltd. in collecting data and taking photographs during the flight.
The author wishes to thank them.

\section{References}

1) E. F. J. Fry and J. S. Hert: J. Fish. Res. Bd. Canada, 7, 169-175 (1948).

2) J. R. Brett: J. Fish. Res. Bd. Canada, 21, 11831226 (1964).

3) J. R. Brett: J. Fish. Res. Bd. Canada, 22, 14911501 (1965).

4) F. W. H. Beamish: J. Fish. Res. Bd. Canada, 23, 341-347 (1966).

5) I. Hara: Bull. Tokai Reg. Fish. Res. Lab., No. 113, 63-74 (1984).

6) I. Hara: Nippon Suisan Gakkaishi, 51, 41-46 (1985).

7) I. Hara: Nippon Suisan Gakkaishi, 51, 19391945 (1985).

8) J. H. S. Blaxter: FAO Fisheries Report, 62, 69100 (1967).

9) R. Bainbridge: J. exp. Biol., 35, 109-133 (1958).

10) Z. Villavicencio, F. Lazo, and G. Contreras: Boletin Instituto del Mar del Peru ISSN Q3787699 Volumen extraordinario, 206-214 (1981).

11) J. R. Brett, M. Hollands, and D. F. Alderdice: J. Fish. Res. Bd. Canada, 15, 587-605 (1958).

12) J. H. S. Blaxter and W. Dickson: J. du Cons., 24, $472-479$ (1959). 